\title{
Evaluasi Kinerja Pustakawan dan Staf Perpustakaan terhadap Kepuasan Pemustaka pada Perpustakaan Darul Ma'arif Madrasah Aliyah Swasta (Mas) Sunan Pandanaran Ngaglik Sleman Daerah Istimewa Yogyakarta
}

\author{
Rr. Siti Fatwa Ubayya Kusuma \\ Perpustakaan Madrasah Aliyah Swasta Sunan Pandanaran Ngaglik Sleman \\ email: ubayyafatwa@gmail.com
}

\begin{abstract}
Abstrak
Perpustakaan yang sempurna yaitu perpustakaan yang dapat menyediakan sumber informasi yang lengkap, fasilitas yang memadai dan pelayanan yang maksimal. Semua faktor tersebut tidak luput dari kinerja seorang pustakawan dan staf perpustakaan yang mumpuni. Kedua unsur perpustakaan tersebut harus mempunyai kemampuan dan dedikasi yang tinggi dalam pengolahan bahan pustaka sebagai sumber informasi. Perawatan fasilitas-fasilitas pendukung akan mampu memberikan pelayanan yang baik. Sehingga pemustaka dapat memanfaatkan sumber informasi secara maksimal dengan nyaman. Tujuan Penelitian ini yaitu tentang evaluasi kinerja pustakawan dan staf perpustakaan terhadap kepuasan kepuasaan pemustaka di perpustakaan Darul Ma'arif (Madrasah Aliyah Swasta) MAS Sunan Pandanaran. Pelayanan pustakawan di perpustakaan Darul Ma'arif MAS Sunan Pandanaran akan diteliti dengan memakai metode kuantitatif. Dengan teknik pengumpulan data memakai kuesioner. Setelah diadakan penelitian secara umum kualitas pelayanan perpustakaan di Darul Ma'arif sudah memuaskan pemustaka dengan tingkat kepuasan senilai 71,90\% sampai 80,48\%. Dari hasil penelitian ini diharapkan pelayanan, akses informasi, dan fasilitas yang ada di Madrasah Aliyah Swasta Sunan Pandanaran bisa ditingkatkan sesuai dengan Standar Nasional Perpustkaan yang berlaku di Indonesia. Degan meningkatkan ini semua penulis berharap kepuasan pengunjung dalam mengakses pertustakaan bisa maksimal
\end{abstract}

\author{
Kata Kunci: \\ Perpustakaan Pelayanan \\ Metode Bahan pustaka
}

\section{A. PENDAHULUAN}

Pada masa modern ini, kebutuhan akan informasi semakin tinggi. Perkembangan informasi juga semakin pesat. Sehingga, masyarakat membutuhkan tempat di mana informasi dapat diperoleh dengan mudah, up to date serta lengkap jangkauan informasi. Perpustakaan, menjawab semua tantangan dalam memenuhi kebutuhan informasi. Kini perpustakaan tidak hanya sekedar sebagai tempat menyimpan koleksi buku tetapi banyak penunjang-penunjang yang disediakan dalam memenuhi kebutuhan masyarakat yang haus akan informasi.

Pustakawan dan stafnya tidak luput dari penyedia informasi dalam sebuah perpustakaan.
Bahkan, pustakawan dan staf perpustakaan yang berdedikasi dan berpengetahuan mumpuni merupakan komponen pokok dalam suatu perpustakaan yang baik. Pelayanan yang ramah dan santun, dalam pengelolaan bahan perpustakaan yang tepat dan handal serta perawatan fasilitasfasilitas perpustakaan yang baik merupakan peran pustakawan dan jajaran stafnya.

Dalam kasus ini peneliti ingin meneliti pelayanan, ketersediaan informasi dan fasilitas yang ada di perpustakaan sekolah Darul Ma'arif Madrasah Aliyah Swasta (MAS) Sunan Pandanaran, Ngaglik, Sleman, D.I.Yogyakarta. Perpustakaan di MAS Sunan Pandanaran mempunyai pustakawan yang latar belakangnya berpendidikan diploma dua (D2) serta 
4 (empat) staf perpustakaan yang berlatar belakang pendidikan Sekolah Menengah Atas yang saat ini masih melaksanakan program pendidikan jenjang Strata 1 (S1) pada berbagai jurusan. Jenis Pelayanan yang disuguhkan terhadap pemustaka yaitu pelayanan terbuka, dimana pemustaka dengan leluasa memilih bahan pustaka yang dibutuhkan yang mana dapat ditelusur melalui alat penelusur katalog manual atau Online Public Acess Catalogue (OPAC).

Dalam peneleitian ini pelayanan yang diteliti ada 3 aspek, yaitu aspek layanan, kontrol informasi dan fasilitas tempat. Dimana 3 aspek ini merupakan komponen pokok dalam pelayanan perpustakaan.

Penelitian ini akan membahas tentang evaluasi kinerja pustakawan dan staf perpustakaan terhadap kepuasan pemustakayang dilakukandiPerpustakaan Darul Ma'arif Madrasah Aliyah Swasta (MAS) Sunan Pandaran. Dari penelitian ini diharapkan bisa memberikan informasi bagi pengunjung tentang evaluasi kinerja pustakawan dan staf perpustakaan terhadap kepuasan pemustaka. Dan diharapkan kekurangan pustakawan dan staf perpustakaan dapat diketahui didalam memberikan pelayanan terhadap pengunjung dan membenahi kekurangan tersebut supaya pelayanan menjadi lebih baik dan memaksimalkan kepuasan pemustaka.

\section{B. KAJIAN PUSTAKA}

Zhubai Zhang (2019) menghasilkan penelitian yang menjelaskan bahwa tujuan dari penelitiannya adalah untuk menentukan hubungan antara lingkungan dalam ruangan dan kinerja pustakawan terhadap kepuasan pemustaka di mana mekanisme hubungan ini dalam kegiatan nirlaba, khususnya perpustakaan. Survei dikirimkan ke perpustakaan universitas di tiga provinsi timur laut. Sebanyak 556 kuesioner wawancara tatap muka yang valid dikumpulkan dan diperiksa dengan uji reliabilitas dan validasi. Model persamaan struktural digunakan untuk menganalisis hubungan antara variabel laten. Hasil analisis regresi berganda secara simultan menunjukkan hasil, bahwa kepuasan pemustaka dipengaruhi secara positif oleh kualitas lingkungan dalam ruangan dan desain interior dengan melalui kinerja pustakawan sebagai variabel intervening. Dengan demikian, kepuasan memilikidampakpositif dan kuat terhadap kinerja pustakawan. Mekanisme pengaruh ditentukan dan itu menunjukkan bahwa untuk meningkatkan kinerja pustakawan, kepuasan pemustaka pertama-tama harus ditingkatkan dengan peningkatan lingkungan dalam ruangan. Studi ini adalah yang pertama untuk menerapkan dan mengintegrasikan teori indeks kepuasan pelanggan lintas lapangan dengan teori evaluasi pasca-hunian untuk menganalisis bangunan nirlaba di wilayah timur laut Cina.

Sementara Iris Xie dkk (2019) dalam hasil risetnya menguraikan, bahwa pengguna tunanetra mengalamikendaladalam lingkungan perpustakaan digital, sebagian besar karena keterbatasan dalam desain perpustakaan digital yang mencegah mereka berinteraksi secara efektif dengan konten dan fitur perpustakaan digital. Penelitian yang ada belum cukup meneliti bagaimana pengguna tunanetra berinteraksi dengan perpustakaan digital, atau masalah khas yang ditemui selama interaksi. Ini adalah studi pertama yang dilakukan untuk menguji apakah penerapan fitur bantuan yang sesuai dengan kebutuhan pengguna tunanetra dapat mengurangi lima situasi pencarian bantuan kritis yang biasanya mereka temui, dengan tujuan untuk lebih meningkatkan kegunaan dari perpustakaan digital. Berbagai metode pengumpulan data termasuk pra-kuesioner, protokol berpikir keras, log transaksi, dan wawancara pencarian sebelum dan sesudah, dipekerjakan dalam desain eksperimental. Empat puluh subjek dibagi menjadi dua kelompok dengan data demografis yang sama berdasarkan data yang dihasilkan dari pra-kuesioner. Temuan penelitian ini menunjukkan bahwa kelompok eksperimental mengalami lebih sedikit situasi mencari bantuan daripada kelompok kontrol 
ketika berinteraksi dengan versi eksperimental dan baseline perpustakaan digital. Selain itu, kelompok eksperimen mengungguli kelompok kontrol pada manfaat yang dirasakan dari fitur perpustakaan digital, kemudahan penggunaan perpustakaan digital, dan kepuasan perpustakaan digital. Studi ini memberikan kontribusi teoritis dan praktis ke bidang perpustakaan dan ilmu informasi. Secara teoritis, penelitian ini membingkai kerentanan pengguna tunanetra dalam model sosial disabilitas di mana desain perpustakaan digital yang tidak tepat merusak kemampuan mereka untuk secara efektif mengakses dan menggunakan perpustakaan digital. Secara praktis, penelitian ini mempertimbangkan situasi pencarian bantuan kritis pengguna tunanetra dan lebih jauh menerjemahkannya ke dalam desain fitur bantuan untuk meningkatkan kegunaan perpustakaan digital.

\section{METODE PENELITIAN}

Penelitian ini dilaksanakan dengan metode kuantitatif dengan teknik pengumpulan data menggunakan teknik delphy study atau pembagian kuesioner. Metode penelitian kualitatif merupakan penelitian yang berfokus pada observasi kejadiankejadian, Fenomena yang diteliti kompleks, bersifat sosial yang tidak dapat dikuantifikasi dan mencoba mengerti perilaku individu yang diamati (Hartinah, 2013). Penelitian dilakukan di Madrasah Aliyah Swasta (MAS) Darul Ma'arif Sunan Pandanaran,
Ngaglik, Sleman pada tanggal 15 Oktober sampai dengan 1 November 2019.

Teknik pengumpulan data menggunakan kuesioner atau teknik delphy study. Teknik delphy study adalah sebuah prosedur penelitian dengan menggunakan kuesioner, yang didesain untuk mendapatkan konsensus melalui respons yang diberikan oleh responden (Hartinah, 2013). Teknik ini dilakukan apabila antara peneliti dan responden tidak dapat bertatap muka langsung, respon dilakukan melalui surat menyurat berkali-kali sampai dicapai suatu konsensus yang diinginkan. (Hartinah, 2013). Pengumpulan data dengan penyebaran angket kepada 35 responden siswa-siswa MAS Darul Ma'arif Sunan Pandanaran. Teknik olah data dengan cara menganalisis dari pengumpulan data responden dan menintepretasikan dari data tersebut sehingga diperoleh hasil dan kesimpulan.

\section{HASIL DAN PEMBAHASAN}

Jumlah responden yang diambil untuk penelitian ini sebanyak 35 orang. Tiap-tiap responden menjawab pertanyaan kuesioner yang telah disediakan. Adapun jumlah pertanyaan dalam kuesioner sebanyak 18 pertanyaan. Dengan rincian 6 pertanyaan mewakili Affect of Service, 6 pertanyaan mewakili Information Control, dan 6 pertanyaan terakhir mewakili As Place. Hasil penelitian ditampilkan di tabel 1.

Dari hasil rekapitulasi kuesioner pada tabel 1 dapat diringkas sebagai berikut;

Tabel 1. Hasil Rekapitulasi Kuesioner

\begin{tabular}{|c|c|c|c|c|c|c|c|c|c|c|}
\hline \multirow{2}{*}{ NO } & \multirow{2}{*}{ RESPONDEN } & \multicolumn{3}{|c|}{ AFFECT OF SERVICE } & \multicolumn{3}{|c|}{ INFORMATION CONTROL } & \multicolumn{3}{|c|}{ AS PLACE } \\
\hline & & $\mathbf{A}$ & B & C & A & B & C & $\mathbf{A}$ & B & C \\
\hline 1 & Responden 1 & 6 & 0 & 0 & 6 & 0 & 0 & 6 & 0 & 0 \\
\hline 2 & Responden 2 & 5 & 1 & 0 & 6 & 0 & 0 & 5 & 1 & 0 \\
\hline 3 & Responden 3 & 6 & 0 & 0 & 6 & 0 & 0 & 6 & 0 & 0 \\
\hline 4 & Responden 4 & 6 & 0 & 0 & 6 & 0 & 0 & 6 & 0 & 0 \\
\hline 5 & Responden 5 & 5 & 1 & 0 & 3 & 3 & 0 & 4 & 2 & 0 \\
\hline 6 & Responden 6 & 6 & 0 & 0 & 6 & 0 & 0 & 6 & 0 & 0 \\
\hline 7 & Responden 7 & 5 & 1 & 0 & 4 & 2 & 0 & 4 & 2 & 0 \\
\hline 8 & Responden 8 & 5 & 1 & 0 & 5 & 1 & 0 & 6 & 0 & 0 \\
\hline 9 & Responden 9 & 6 & 0 & 0 & 5 & 1 & 0 & 6 & 0 & 0 \\
\hline 10 & Responden 10 & 5 & 1 & 0 & 5 & 1 & 0 & 6 & 0 & 0 \\
\hline 11 & Responden 11 & 6 & 0 & 0 & 6 & 0 & 0 & 5 & 1 & 0 \\
\hline
\end{tabular}




\begin{tabular}{|c|c|c|c|c|c|c|c|c|c|c|}
\hline 12 & Responden 12 & 1 & 5 & 0 & 4 & 2 & 0 & 3 & 3 & 0 \\
\hline 13 & Responden 13 & 3 & 3 & 0 & 5 & 1 & 0 & 6 & 0 & 0 \\
\hline 14 & Responden 14 & 4 & 2 & 0 & 5 & 1 & 0 & 5 & 1 & 0 \\
\hline 15 & Responden 15 & 3 & 3 & 0 & 3 & 2 & 1 & 6 & 0 & 0 \\
\hline 16 & Responden 16 & 6 & 0 & 0 & 4 & 2 & 0 & 4 & 2 & 0 \\
\hline 17 & Responden 17 & 4 & 2 & 0 & 6 & 0 & 0 & 6 & 0 & 0 \\
\hline 18 & Responden 18 & 2 & 4 & 0 & 5 & 1 & 0 & 5 & 1 & 0 \\
\hline 19 & Responden 19 & 1 & 4 & 1 & 4 & 1 & 1 & 6 & 0 & 0 \\
\hline 20 & Responden 20 & 5 & 1 & 0 & 2 & 3 & 1 & 3 & 3 & 0 \\
\hline 21 & Responden 21 & 5 & 1 & 0 & 4 & 2 & 0 & 3 & 3 & 0 \\
\hline 22 & Responden 22 & 5 & 1 & 0 & 5 & 1 & 0 & 5 & 1 & 0 \\
\hline 23 & Responden 23 & 4 & 2 & 0 & 5 & 1 & 0 & 4 & 1 & 1 \\
\hline 24 & Responden 24 & 6 & 0 & 0 & 4 & 2 & 0 & 6 & 0 & 0 \\
\hline 25 & Responden 25 & 6 & 0 & 0 & 2 & 4 & 0 & 6 & 0 & 0 \\
\hline 26 & Responden 26 & 5 & 1 & 0 & 5 & 1 & 0 & 5 & 1 & 0 \\
\hline 27 & Responden 27 & 6 & 0 & 0 & 3 & 3 & 0 & 5 & 1 & 0 \\
\hline 28 & Responden 28 & 6 & 0 & 0 & 3 & 3 & 0 & 4 & 2 & 0 \\
\hline 29 & Responden 29 & 6 & 0 & 0 & 4 & 2 & 0 & 3 & 3 & 0 \\
\hline 30 & Responden 30 & 6 & 0 & 0 & 3 & 3 & 0 & 5 & 1 & 0 \\
\hline 31 & Responden 31 & 5 & 1 & 0 & 5 & 1 & 0 & 5 & 1 & 0 \\
\hline 32 & Responden 32 & 5 & 1 & 0 & 4 & 2 & 0 & 6 & 0 & 0 \\
\hline 33 & Responden 33 & 6 & 0 & 0 & 2 & 3 & 1 & 4 & 2 & 0 \\
\hline 34 & Responden 34 & 2 & 3 & 1 & 1 & 3 & 2 & 0 & 3 & 3 \\
\hline 35 & Responden 35 & 4 & 2 & 0 & 5 & 1 & 0 & 4 & 1 & 1 \\
\hline & Jumlah & 167 & 41 & 2 & 151 & 53 & 6 & 169 & 36 & 5 \\
\hline & Persentase & $79,52 \%$ & $19,52 \%$ & $0,95 \%$ & $71,90 \%$ & $25,24 \%$ & $2,86 \%$ & $80,48 \%$ & $17,14 \%$ & $2,38 \%$ \\
\hline
\end{tabular}

Sumber: data primer diolah $\mathrm{N}=35,2019$

Tabel 2. Ringkasan Hasil Rekapitulasi Kuesioner

\begin{tabular}{|c|c|c|c|c|c|c|c|c|}
\hline \multicolumn{3}{|c|}{ AFFECT OF SERVICE } & \multicolumn{3}{|c|}{ INFORMATION CONTROL } & \multicolumn{3}{|c|}{ AS PLACE } \\
\hline A & B & C & A & B & C & A & B & C \\
\hline $79,52 \%$ & $19,52 \%$ & $0,95 \%$ & $71,90 \%$ & $25,24 \%$ & $2,86 \%$ & $80,48 \%$ & $17,14 \%$ & $2,38 \%$ \\
\hline
\end{tabular}

Sumber: data primer diolah $\mathrm{N}=35,2019$

\section{Keterangan: $A$ = puas; $B$ = kurang puas;}

\section{$\mathrm{C}=$ tidak puas}

Berdasarkan tabel diatas diperoleh informasi sebagai berikut:

1. Tingkat kepuasan untuk pelayanan sebanyak $79,52 \%$, yang kurang puas terhadap pelayanan sebanyak 19,52\%, dan yang tidak puas terhadap perlayanan sebanyak 0,95\%.

2. Tingkat kepuasan terhadap ketersediaan informasi perpustakaan sebanyak 71, 90\%, yang kurang puas sebanyak $25,24 \%$ dan yang tidak puas sebanyak 2,86\%.

3. Tingkat kepuasan terhadap fasilitas perpustakaan sebanyak $80,48 \%$, yang kurang puas sebanyak $17,14 \%$ dan yang tidak puas sebanyak $2,38 \%$.
Tingkat kepuasan yang tinggi pengunjung perpustakaan merupakan ukuran keberhasilan didalam pelayanan. Poin penting perpustakaan terletak pada bidang pelayanan. Keberhasilan pengadaan perpustakaan ditentukan oleh kepuasan pemustaka dan dapat diketahui dari banyaknya pemustaka yang berkunjung ke perpustakaan untuk mengakses informasi yang diinginkan. Banyaknya pemustaka yang berkunjung ke perpustakaan dipengaruhi oleh banyak hal. Hal-hal yang mempengaruhi banyaknya kunjungan ke perpustakaan adalaj salah berasal dari pengelola perpustakaan itu sendiri, perpustakaan harus diolah oleh pustakawan dan staf yang kompeten dan profesional serta dedikasi yang tinggi untuk memberikan pelayanan yang optimal.

Keberhasilan pelayanan di perpustakaan bukan dilihat dari informasi yang diberikan saja, akan tetapi dipengaruhi juga oleh kepuasan terhadap pelayananan pustakawan. Sikap pustakawan terhadap pemustaka menjadi hal pokok bagi kepuasan pemustaka terhadap pelayanan yang 
disajikan.

Guna memaksimalkan kepuasan pemustaka maka pihak perpustakaan perlu adanya saran kritik, serta masukan dari pemustaka, faktor ini perlu dilaksanakan supaya pustakawan serta staf mengerti apa saja yang diinginkan oleh pemustaka dan apa yang harus dikerjakan oleh pustakawan agar bisa memenuhi kepuasan pelayanan terhadap pemustaka. Hal ini akan membentuk hubungan harmonis diantara pemustaka, pustakawan dan staf dalam pemenuhan kebutuhan informasi dan fungsi perpustakaan yang maksimal.

Perpustakaan Darul Ma'arif menyuguhkan pelayanan bahan-bahan pustaka yang tersusun dari layanan sirkulasi layanan membaca, dan layanan referensi di perpustakaan, layanan penelusuran informasi (Komputer Publik), Layanan Foto Copy. Layanan sirkulasi adalah layanan peminjaman bahan pustaka kepada para pemustaka bagi anggota perpustakaan. Hal ini dengan ketentuan pemustaka sudah memenuhi syarat untuk meminjam buku di perpustakaan. Adapun layanan referensi diberikan kepada pemustaka bila pengguna hanya mencari referensi tanpa peminjaman buku. Adapun contoh bahan referensi perpustakaan adalah Ensiklopedia, kamus, direktori, dan sebagainya. Sedangkan pelayanan membaca di perpustakaan, yaitu pelayanan kepada pemustaka yang membaca saja tanpa mempunyai tujuan untuk peminjaman buku, pemustaka telah diberikan fasilitas yang nyaman dan ruangan yang dapat dilihat langsung oleh petugas perpustakaan. Pelayanan penelusuran informasi melalui komputer publik adalah layanan penelusuran referensi sebagai penunjang kebutuhan informasi dan referensi yang lebih luas. Sedangkan layanan fotocopy adalah layanan penggandaan referensi bagi pengguna apabila sumber referensi tidak dapat dipinjam sehingga dapat digandakan.

Dalam pelayanan, perpustakaan Darul Ma'arif menerapkan sistem layanan terbuka, melalui
Online Public Access Catalogue (OPAC) atau melalui katalog manual. Kebaikan sebuah perpustakaan adalah tanggung jawab pustakawan dan staf perpustakaan sebagai pengelola. Maka sebab itu, pelayanan yang baik,maksimal dan terpadu dapat meningkatkan mutu serta citra baik perpustakaan di mata masyarakat sekolah.

Dari hasil penelitian sebagian besar pemustaka menyatakan puas dalam mendapatkan pelayanan oleh pustakawan dan staf perpustakaan dalam pelayanan proses peminjaman koleksi. Namun keramahan dan kesantunan pustakawan dan staf perpustakaan masih dalam taraf cukup puas. Sikap serta pendekatan komunikasi antar pribadi pustakawan dan staf terhadap pemustaka menjadi suatu faktor penting agar pemustaka nyaman dan ketaguhan berkunjung ke perpustakaan.

Dari segi kontrol informasi, sebagian pemustaka merasa cukup puas dengan pelayanan pustakawan dan staf sehingga memudahkan mendapatkan sumber informasi yang dibutuhkan. Namun, fasilitas serta koleksi yang belum mencukupi bagi perpustakaan Sekolah Menengah Keatas menyebabkan sumber informasi masih belum terpenuhi dilihat dari segi koleksi tercetak yang dimiliki. Tetapi dapat didukung dengan adanya fasilitas komputer publik.

Ditinjau dari tempatnya, perpustakaan Darul Ma'arif dirawat dengan baik oleh pustakawan dan staf perpustakaan,walau luas belum memadai standar perpustakaan sekolah, tetapi nyaman dengan penataan dan kebersihan yang terjaga. Sehingga pemustaka merasa betah di perpustakaan.

\section{E. PENUTUP \\ Simpulan}

Berdasarkan penelitian diatas, penulis dapat merumuskan kesimpulan sebagai berikut :

1. Tingkat kepuasan terhadap pelayanan sebanyak 79,52\%, yang kurang puas terhadap pelayanan sebanyak $19,52 \%$, dan yang tidak 
puas terhadap perlayanan sebanyak 0,95\%. Secara umum tingkat kepuasan terhadap pelayanan lumayan bagus karena mendekati nilai $80 \%$.

2. Tingkat kepuasan terhadap ketersediaan informasi perpustakaan sebanyak 71, 90\%, yang kurang puas sebanyak $25,24 \%$ dan yang tidak puas sebanyak 2,86\%.

3. Tingkat kepuasan terhadap fasilitas perpustakaan sebanyak $80,48 \%$, yang kurang puas sebanyak $17,14 \%$ dan yang tidak puas sebanyak 2,38\%. Berdasarkan data ini bisa disimpulkan yaitu tingkat kepuasan terhadap fasilitas tempat perpustakaan bagus, hal ini bisa dilihat dari prosentasenya.

\section{Saran}

1. Untuk meningkatkan tingkat kepuasan terhadap pelayanan di perpustakaan diharapkan pustakawan bisa bersikap lebih ramah, lebih santun terhadap para tamu yang berkunjung ke perpustakaan.

2. Berdasarkan penelitian tersebut tingkat kepuasan terhadap kertersediaan informasi kurang, untuk itu pihak madrasah perlu menambah fasilitas yang menunjang ketersediaan informasi yang dibutuhkan pengunjung perpustakaan.

3. Untuk meningkatkan kepuasan pemustaka terhadap fasilitas perlu ditambah fasilitas yang menunjang perpustakaan sesuai standar nasional.

\section{DAFTAR PUSTAKA}

Basuki, Sulistyo. (2010). Pengantarllmu Perpustakaan. Tangerang Selatan: Universitas Terbuka. Hartinah, Sri. (2013). Metode Penelitian Perpustakaan. Tangerang Selatan: Universitas Terbuka. Iris Xie dkk. (2019). Enhancing usability of digital libraries: Designing help features to support blind and visually impaired users. Information Processing \& Management Available online 16 September 2019, 102110

Martoatmodjo, Karmidi. (1999). Pelayanan Bahan Pustaka. Tangerang Selatan: Universitas Terbuka.

Rumani, Sri. (2014). Aspek Hukum dan Bisnis Informasi. Tangerang Selatan: Universitas Terbuka.

Sudarsana, Undang dan Bastiano. (2010). Pembinaan Minat Baca. Tangerang Selatan: Universitas Terbuka.

Zhubai Zhang (2019). The effect of library indoor environments on occupant satisfaction and performance in Chinese universities using SEMs. Building and Environment Volume 150, March 2019, Pages 322-329. 